\title{
Imagens do Brasil pelas lentes estrangeiras (sob a luz do cinema de ficção) \\ Antonio Carlos (Tunico) Amancio
}

\section{RESUMO}

Este trabalho é uma reflexão sobre a representação do Brasil e dos brasileiros nos filmes estrangeiros de longa metragem de ficção. Ele se situa no dominio dos estudos culturais e se rege pela observação de um certo número de estereótipos e clichês sobre o assunto. Um grupo de figuras alegóricas buscadas nos textos europeus do séculos XVI, permitiu a organização do extenso corpus de filmes europeus e americanos abordados, visando estabelecer uma leitura que levasse em conta a recorrência histórica de temas e motivos.

\section{ABSTRACT}

This paper is a study about the representations of Brazil and Brazilians in long ficcional movies from foreign countries. The paper is placed within the field of Cultural Studies and aims at investigating a number of stereotypes and cliches concerning the subejct matter. A group of alegorical figures found in sixteenth-century European texts was the point of departure for the organization of the extensive number of European and American movies considered in the research, aiming at the establishment of a reading which considered the historical recurrence of themes and motifs.

Antonio Carlos (Tunico) Amancio é doutor pela ECA-USP, professsor do mestrado em Comunicação, Imagem e Informação e do departamento de Cinema da Universidade Federal Fluminense. 
Quando o europeu inventou o Brasil, trouxe consigo seu códiggo de leitura do mundo e seu modo de operar com a realidade. A fusão dessas práticass suscitou uma retórica definiclora de um país que permanece no imaginário euro-americano de uma forma praticamente imutível. Poderíamos pensar essa retórica como um subtexto de qualificação.

Se alentarmos para certas observações já contidas nos documentos fundadores de nossa cultura, veremos o quanto clas se conservam presentes. Ainda que atualizados, tais conjuntos de imagens são recomentes e normalmente diluídos por uma banalização. Eles têm a ver como impacto da paisagem exuberante e com o espanto sobre a condula singular das gentes dacuele mundo novo - c o estabelecimento dessal alteridade radical vai marcar a visão dos trópicos de maneira incuestionável. O processo de sedimentação dessas figguras não vai ser aqui discutido, pois para isto teríamos de refazer toda a rota da circulação das informaçồes sobre o Brasil, e esse trânnsito é imensurável. Se nos mantivermos estritamente na lógica dos descobrimentos. vale a pena referir a visibilidade das imagens do Brasil ainda nos séculos XVI e XVII, postas em circulação a partir de farta correspondencia, coleções de gravuras, manuscritos diversos. iconografia variada, mapas e publicações que já foram exiustivamente estudiados'. Quando as trazemos para os dias de hoje. pensadas em sta attalização, verificamos que as imagens de um certo Bralsil se nutrem e se contaminam de filmes, de música, de quadrinhos, de romance. de tele-

130 novelas. de jingles que se projetam lá forá obedecendo a muitas outras artimanhas do olhar. É um olhar que apreende e reproduz um dos inúmeros Brasis possíveis, umit das possíveis reduçoes que brilham nas telas dos cinemas indicando nosso território geogrático, nosso apparato administrativo e nossas gentes.

Como parte da estratégia de nosso trabalho. vamos utilizar al Cartia de Caminhale emblema de toda esta dispersĩo de informaçóes. selecionando dela algumas referencias essenciais.

A carta de Caminha nos permitirá destacar, com a necessária simplificação. a existência de três focos precisos: a visão utópicia, al observação do cronista e o exílio do degredado. Elas sintetizam perspectivals diferentes de usufruto da terra brasileira e de convívio com as gentes nativas e. se em ilguns momentos tais recortes podem se confundir entre si, a maioria dias vezes eles conduzem at um sentido próprio. É este primeiro sentido que vamos tomar aqui, como se fossem alegorias de um sentide maior. para que alcancemos os fins pretendidos.

A perspectiva utópica está inscrita na própria visãa de Novo Mundo. cuja descoberta coincide com o lançamento da Utopia de Thomas Morus, em 1516. Utopia, formada de duas palavras gregas significando um näo lugare, numa formação linguiistica clue pretende dar conta de un 
"algures" radical, fora do mundo, um lugar abstrato de experimentação. Assim, utopia, mito, quimera, miragem, febre de exotismo, formam todo um repertório conceitual que vai atualizar uma variada mitologia sobre 0 Paraíso terrestre ( já analisada por Sérgio Buarque de Holanda em Visão do Paraíso ${ }^{3}$ ). Uma visão que se funda num desenraizamento do mundo presente e combina a generosidade da natureza com a não exigência dos rigores do trabalho, numa "paisagem de ócio" propiciadora da plena felicidade, numa dimensão onírica de evasão por insatisfação.

Nossa primeira figura trabalha com a moldagem desse fora-do-mundo feito de devaneio e de imaginação desenfreada, o território infinito da utopia mística, o território indefinido da utopia histórica, o território deslocalizado da utopia geográfica, e o território desnaturalizado da utopia sexual. É quando os homens se perdem nos meandros da imaginação.

Pois o cinema estrangeiro realiza esta premissa concernente ao Brasil, numa série de filmes que evocam um país abstrato onde se deposita o desejo de satisfação dramática dos personagens. Morte na Bósnia, Loucos e nervosos, Manhunt in the jungle, Eldorado, A missão, A Colônia $\mathrm{Cecili}^{4}$ serão alguns títulos que vão se inserir nesta perspectiva. Mas é o filme "Brazil", de Terry Gillian, que vai explicitar melhor as tais premissas. Feito em 1985, na Inglaterra, o filme trabalha com uma imagem etérea de Brasil, sintetizada no acompanhamento musical de um homem que sonha voar para a liberdade. O Brasil é apenas essa evocação distante, essa sugestão melódica feita de um escapismo ligeiro, essa outra realidade radical, essa projeção imaginativa que a canção Aquarela do Brasil vai sustentar na ficção. Sem a necessidade de imagens estereotipadas que a sustentem, apenas os acordes musicais fazem a base emocional onde a significação se revela. Esta é a Utopia em seu estado puro, esse lugar fora da sociedade opressora e militarizada que o filme apresenta fora de toda a circunstância inglesa, fora de toda história. A Utopia é um desejo puro de evasão.

Assim são os filmes que usam o Brasil numa perspectiva utópica, cheios de sugestões, de referências veladas, de vontades insubmissas, que a distância e o desconhecimento de outras terras podem fazer emergir.

Mas quando a verificação é feita in loco, o contato é direto e a leitura é definitivamente outra. Assim são os filmes englobados na figura alegórica do cronista, este Pero Vaz moderno que investiga a realidade brasileira, enquadra e recorta, evidencia ou esconde, enfatiza ou ignora. São os filmes passados aqui ( sejam filmados aqui ou não), e neles percebemos algumas dominâncias, correspondentes ao precário equilíbrio da balança de troca de bens simbólicos entre o Brasil e o mundo desenvolvido, onde a atividade cinematográfica ocupa papel de destaque.

São, em geral, filmes que promovem uma simplificação ingênua da 
realidade, uma exploração equivocada da geografia, uma constatação redutora dos costumes e das gentes. Filmes apressados onde o Brasil se apresenta com um menso cenário de fundo e onde os brasileiros interpretam um papel secundário. Filmes que evidenciam uma apropriação imaginária baseada exatamente na exuberância da paisagem e na conduta inusitada das gentes. Natureza e folclore. O clichê gcográlico e a estereotipagem antropológica. A terra generosa e o povo amigível e feliz. Assim é o Brasil do cinema estrangeiro, a maioria das vezes. Salvaguardado pelas honrosas exceções.

O cinema cronista é também um cinema viajante, reproduzindo os caminhos do passado, os grandes périplos pelo país, pelas vistas consagradas pelo turismo, pelas manifestações populares mais difundidas, quase sempre embaladas pela músical nativa para dar a necessária cor local. Mas o cinema cronista às vezes se alimenta também da política.

Como nos anos 40, forjado nos meandros da Política da Boa Vizinhança de Franklin Delano Roosevelt, que pretendia uma cooperação estrcita entre as nações da América, diminuindo a influência européia, principalmente alemã, e promovendo a estabilidade política no continente. O cinema vai ser peça chave nesse processo e vai gerar um intenso intercâmbio entre Estados Unidos e Brasil. Carmen Miranda e Orson Welles, entre outros, vĩo garantir a excelência desses mercados de trocil, Walt Disney vai fazer aqui seus desenhos animados que vão ser, a partir de 132 então, marcas definidoras de uma grafia tropical, o Zé Carioca e os Quindins de Yayá, o casario colonial e as calçadas de Copacabana, o movimentado samba e as orquídeas coloridas. Neste rastro vamos ter filmes que valorizam os cassinos, os hotéis de luxo, os cruzeiros elegantes e por pouco Bette Davis (A estranha passageira, EUA, 1942, Irving Rapper) c Ingrid Bergman (Interliclio. EUA, 1946, Alfred Hitchcock) não se encontram no Rio de Janeiro, por conta da magia do uso das imagens de estoque. A partir de uma valorização de aspectos culturais singulares, os filmes vão sedimentar um repertório de imagens sobre o Brasil que vai permanecer por muito tempo. Os anos 50 ainda verão um Brasil feito em estúdio, centrado na capital do país, onde predominam as tramas amorosals e as velhas mitologias edênicas são trazidas à tona.

No final da década será a vez dos europeus, capitaneados pelos franceses, que vão tentör recuperar um mercado perdido ao cinema americano c vão estimular as co-produções e os festivais internacionais. Na linha de mira, o Brasil. E aí vão surgir "Orfen do camaval"( FRA, 1959, Marcel Camus) e uma série de filmes-périplo, que vão sc interessar pelo registro do país em variado diapasão, incluindo a novidade arquitetônical de Brasília, al exuberância tropical da Amazônia, a tradição litorânea do Nordeste e a espetacularidade das quedas do Iguaçu. O país vai ser es- 
quadrinhado por personagens diversos, agentes secretos, exploradores e espertalhões que vão revolver o Brasil à procura de tesouros e riquezas em "O homem do Rio", "Fúria na Bahia", "Os bandeirantes", durante os anos 60 .

O Brasil edênico e divertido, a locação rica e exótica, o povo generoso e musical passam a sofrer os rigores da ditadura militar e o cinema estrangeiro acompanha lá de fora os acontecimentos. Poucos se interessam pelo assunto, mas referências esparsas contaminam o cinema de CostaGavras, de Godard, de Gilo Pontecorvo. O país quase some do mapa cinematográfico estrangeiro.

O final dos anos 70 vê o ressurgimento do interesse pelo Brasil, de novo pela ótica do turismo, desta vez dentro de uma chave extremamente masculina e vigorosa - associada aos resquícios da Guerra Fria - por conta da performance do espião 007, em defesa do capitalismo no Bondinho do Pão de Açúcar ou nas quedas de Iguaçu, lutando contra "O foguete da morte"( ING, 1979, Lewis Gilbert). Quase refeito em sua pujança, o país será de novo o palco de aventuras dos novos heróis contemporâneos, onde não faltarão os remanescentes dos Sex Pistols, Bud Spencer e Terence Hill e Emmanuelle. O Brasil é o cenário para todas as tribos. Até mesmo Demi Moore vai dar as caras por aqui numa comédia de Stanley Donen, "Feitiço do Rio"( EUA, 1984), onde o Brasil será ainda o país do topless, do exotismo, da caricatura dos rituais afro, de uma sedução que se desloca da paisagem e contagia as gentes em frenética celebração sensual. Agora o cinema estrangeiro celebrará o Brasil urbano, da especulação imobiliária, da integração racial, da mestiçagem cultural. E acima de tudo, da transgressão sexual, um império de prostitutas e travestis invadindo as telas e dominando as tramas. "Orquídea selvagem"(EUA, 1990, Zalman King) encerra a década, promovendo, por artes da montagem, a fusão arbitrária de duas cidades, Rio e Salvador, que se tornam a mesma metrópole imaginária, cheia de prazeres e de inquietantes submissões sexuais. Os brancos personagens principais deslizam suas neuroses em meio a um coro mestiço que proclama as liberalidades do amor. Criadas tais separações, o filme demonstra sua intransitividade, em que sexo e perspectiva amorosa se isolam, numa atmosfera de batuques e lambada. O Brasil moderno e urbano vira, então, o refúgio dessas gentes em busca de uma sexualidade plena.

Mas os anos 90 vão revelar uma outra cara do Brasil, sob o ponto de vista dos filmes-crônica, e um novo assunto vai ocupar o primeiro plano: a questão ecológica da preservação da Amazônia e o destino dos povos das florestas. A devastação ambiental, o genocídio indígena, e os males da civilização serão tratados, neste último pólo edênico do Ocidente, com alguma atenção, em obras como Brincando nos campos do Senhor, Le 
juguar. Amazônia, of filme, ", em contraponto às leituras simplificadoras ou caricaturais como Amazônia em chamas e Lambada, a dança proibida. Incorporado ao temário brasileiro. o assunto vai ser ponto de partida parar uma série de produções que vão pensar tal território da superficialidade à exaustão. Não faltarão nos filmes indicativos da presença militar estrangeira na Amazônia, da denúncia da escravidão humana, juntamente com a exploração abusiva de uma mitologia edênica espetacular como uma inabolizada Anaconda e seus sucedâneos monstruosos.

Enquanlo se repensa a floresta, se representa a crise urbana de forma incisiva, um exército de excluídos ganhando voz nas telas, meninos de ruil. escravals brancas, drogados e traficantes - at serpente do mal invadindo o paraíso en filmes como Kickborer III (EUA. Rick King, 1992) ou mesmo o Boca (EUA, Zalman King, 1995). O cenário ideal é desfeito, o cinemal olha agora o Brasil com os olhos do terceiro mundo. O Brasil das tclas é mais próximo do Brasil das ruas, enquanto sobrevivem aqui e ali distorções claras do olhar viajante inebriado pelas velhas mitologias.

Falamos da Utopia, falamos do cronista, mostramos rapidamente como uma imagem do Brasil e dos brasileiros evolui nas telas dos cinemas, quando observadas pelas lentes estrangeiras. Falta apenas o degredado. E vamos recorrer de novo à Carta de Caminha, para lembrar de Afonso Ribeiro, símbolo dos poucos personagens que ficam aqui, encerrada a ivventura da descobertia, que vai dar, no futuro, lugalr ao esforço da 134 colonizaçĩo. Este homem que simboliza, no dizer de Palulo Prado, a "escuma turva das velhas civilizações"s, aquele que num território edênico buscá soltar, exaltado pela ardência do clima, seu sensualismo de aventureiro e conquistador, repelindo a organização da sociedade européia. Corsírios, flibusteiros, caçulas das antigas famílias nobres, jogadores allruinados, padres revoltados ou remissos, pobres diabos, vagabundos dos portos do Mediterrâneo; anarquistas, em suma, na expressão moderna, e insubmissos às peias sociais - foi deles o Novo Mundo, nesse alvorecer e todo o continente se povoou desses adventícios violentos e desabusados.

É irresistível não fazer a devida atualização, referendada pelo cinema. Porque ela justifical o olhar euro-americano que descreve o Brasil nos filmes onde ela formaliza os degredados modernos, figura cuja especifidade não rege as relações com os outros países latinos do continente. Porque o degredado moderno, figura constante num sem número de filmes. é aquele personagem desonesto que, por esforço ou sorte, deve fugir de seu parís, para não prestar contas à sua justiça. Encurralado pela lei, a fuga é sua última saída. A fuga e o cxílio, a busca de uma nova identidade e a recomposição de sua vida em novas bases.

E para onde fogem os degredados do cinema, quando decidem como rumo o sul do continente? Para o Chile? Para o Uruguai? Parä a Argenti- 
na? Não, eles fogem para o Brasil, essa terra tropical, de gentes amistosas, que não têm lei, nem rei, nem fé, como já diziam os antigos. Um país cuja política de extradição abrigou generosamente o ladrão inglês Ronald Biggs, objeto aliás de um filme "O Prisioneiro do Rio" (EUA, 1988, Lech Majewski) e alegoria máxima do degredado contemporâneo, só recentemente (2001) retornado à sua terra.

Foge-se para o Brasil por várias razões: foge-se do vício do jogo, da perseguição de psicopatas, por razões políticas, foge-se de casamentos falidos, foge-se de maridos traídos, foge-se com o fruto de um ajuste de contas de uma vingança familiar ou conseguido através de negociações excusas. Enfim, foge-se por qualquer motivo, dramático ou cômico. Mas, em que pese a existência de algumas variações, o modelo original, calcado na fuga da justiça lá fora ou de outro agente reparador, institucional ou marginal, é ainda o mais constante. É, em geral, o fruto de um roubo que vai desencadear um projeto de busca de um espaço novo de vida. A variação nesta situação dramática é mínima. Desde 1951 o cineasta inglês Charles Chrichton faz alguns de seus personagens fugirem para o Brasil, de "O Mistério da Torre (ING, 1951) a "Um peixe chamado Wanda" (ING, 1988), neste último por conta de um precioso diamante roubado. Os espertalhões de "Freiras em fuga" (ING, 1990, Jonathan Lynn) vêm para cá com enorme soma roubada de gangsters, o herói Pierre, do filme francês "Mona e Moi"(FRA, 1989, Patrick Grandperret) quer fugir para o Brasil para fazer tráfico de qualquer coisa, diferentemente dos ladrões de "Les arcanailers", (FRA, 1991, Manuel Sanchez) que querem vir para o Brasil sem mesmo saber qual língua se fala aqui. Karen McCoy foge para o Brasil com o fruto de um "Grande assalto" (EUA, Russel Mulcahy, 1993), a mocinha de "Cova Rasa" (ING, Danny Boyle, 1994) quer fazer o mesmo. O motorista de táxi de "Sádica perseguição "(EUA, 1992, Mark Lester) traz uma mala de dólares.

Todo mundo já viu um filme em que o ladrão foge para o Brasil no final.

Em geral, esse impulso para vir para o Brasil não é nem justificado, nem motivado especialmente. Raramente um personagem explicita o porquê dessa escolha como opção de escape da lei ou de qualquer outro agente reparador. O recurso ao Brasil como etapa final de uma fuga é uma espécie de deus-ex-machina, um expediente fácil que permite à solução dramáticł uma certa dose de eficiência. Afinal de contas os filmes raramente explicam porque se foge tanto para o Brasil.

E nem nós vamos explicar. Só vamos recordar o início de nossa conversa, falando de um subtexto de qualificação, de um imaginário contaminado por velhas idéias que proliferam em novos veículos, numa estranha sina de periferia, de descaso, de vulgarização de que o cinema comercial 
de ficção é território exemplarr. Pensada como mercadoria, a imagem do Brasil nos filmes estrangciros vale mais pelo que esconde, da fala dos outros, do que pelo que revela cm seus estereótipos e clichês.

\section{Notas}

1 Por exemplo, por Ronald RAMINELLI em "Imagens da colonização: a representação do índio de Caminha a Vieira". Rio de Janeiro: Zahall, 1996

2 Mesmo tendo em vista que a Carta só foi publicada na íntegra $\mathrm{em}$ 1817, pelo Padre Manuel Aires Cabral.

3 HOLANDA, Sérgio Buarque de. Visão do Paraíso. São Paulo: Brasiliense, 1992

4 Morte na Bósnial (OST, 1990, Peter Patzak); Loucos e nervosos (EUA, 1991, Rocky Lang) Manhunt in the jungle (EUA, 1958, Tom McGowan), Eldorado (ESP. 1987, Carlos Saura) A missão (ING, 1986, Roland Joffé), A Colônia Cecília (FRA. 1975. Jean-Louis Comolli)

5 O Homem do Rio (FRA, , 1964, Philippe de Brocal), Fúria na Bahia (FRA, 1965, André Huncbelle), Os bandeirantes ( FRA, 1960, Marcel 136 Camus).

6 EUA, Hector Babenco, 1991; FRA, 1995, Francis Veber; FIN, Mika Kaurismaqui, 1990

7 EUA, 1993, John Frankenheimer; EUA, 1994, Greydon Clark.

8 PAULO PRADO - Retrato do Brasil . 8 ed. São Paulo: Companhia das Letras , 1997, p. 66

Palavras-chave:

1. representação filmica

2. estereótipos cinematográficos

3. filmes estrangeiros

4. imagens do Brasil

5. estudos culturais 